\title{
Percepção de pais e professores da influência de um programa motor inclusivo no comportamento social de crianças portadoras e não-portadoras de necessidades especiais ${ }^{1}$
}

Marcelo Milano Guaragna* Rosiane Karine Pick ** Nadia Cristina Valentini***

Resumo: Esta pesquisa teve como objetivo investigar as percepções de pais e professores sobre possíveis mudancas no comportamento social, bem como a repercussão do processo inclusivo de crianças portadoras ou não de necessidades especiais, com atrasos motores, que participaram de uma intervenção motora inclusiva durante 14 semanas. A partir de uma entrevista semi-estruturada, da qual participaram os pais e professores, constataram-se mudanças positivas quanto às seguintes características: interação social, autonomia, confiança, responsabilidade, bem como a diminuição da agressividade. Quanto ao processo inclusivo, o convívio e a aceitação da diferença permitiram a superação de dificuldades motoras e sociais de algumas das crianças.

Palavras-chave: intervenção motora, atraso motor, comportamento social, inclusão.

\section{Introdução}

O desenvolvimento humano acontece pela interação do indivíduo e do meio ambiente, sendo que o impacto do ambiente pode ser evidenciado nas diferentes facetas do desenvolvimento - físico, cognitivo e social (BEE, 1996). A socialização, caracterizada por um processo de interação e desenvolvimento em que o ser humano aprende a conectar-se com o mundo social que o cerca (COAKLEY, 1993),

* Professor de Educação Física pela Universidade Federal do Rio Grande do Sul.

** Mestre em Ciências do Movimento Humano pela Universidade Federal do Rio Grande do Sul.

*** Doutora em Educação Física. Professora adjunta da Universidade Federal do Rio Grande do Sul.

1 Os autores agradecem o auxílio do Professor Doutor Adroaldo Gaya no delineamento metodológico do presente estudo.

Movimento, Porto Alegre, v. 11, n. 1, p.89-117, janeiro/abril de 2005 
ocorre por meio da observação, da inferência, e de tentativas e erros; porém, a forma mais expressiva de socialização ocorre mediante a interação social com outros indivíduos. É através da interação social que o indivíduo obtém informações sobre a sociedade em que vive e sobre si próprio, construindo na socialização a sua humanidade (PAYNE e ISSACS, 2002).

Por meio de interações sociais, a criança aprende a relacionarse com pares e adultos e a colocar-se no lugar dos outros; adquire novos comportamentos observando o comportamento dos outros (BANDURA, 1979; PAPALIA, 1998); reveza-se em papéis de comandar e seguir (ROOPNARINE e FIELD apud PAPALIA, 1998); resolve problemas cooperativamente e independentemente (VYGOTSKY, 1998). A construção e a manutenção de amizades são fundamentais, portanto, para o desenvolvimento integral da criança. As amizades na infância mediam: 1) o enriquecimento das habilidades comunicativas, cognitivas e sociais, além de proporcionarem proteção e sensação de bem-estar (GRENOT-SCHEYER apud BISHOP, 1999); 2) a aprendizagem de comportamentos adequados ao gênero e a incorporação desses papéis no autoconceito (PAPALIA, 1998); 3) o ajuste das necessidades e dos desejos individuais às necessidades e aos desejos dos outros, na hora de ceder e no momento de sustentar uma postura pessoal (PAPALIA, 1998); 4) o fortalecimento de sentimentos de pertencimento, de identidade, liderança e cooperação (PAPALIA, 1998), principalmente no contexto escolar.

O contexto escolar propicia à criança oportunidades de enfrentar desafios, conquistar e dominar novas habilidades. A satisfação experimentada com as conquistas auxilia a criança na construção de julgamentos positivos sobre suas habilidades motoras, cognitivas e sociais, e a ganhar confiança nas suas ações (BEE, 1996), contribuindo, dessa forma, para a construção da autonomia para aprender (VALENTINI e RUDISILL, 2004a). Além disso, crianças que fazem novas amizades na escola tendem a obter escores mais altos em testes de desempenho escolar. Em contrapartida, crianças rejeitadas pelos colegas criam aversão à escola, faltam mais e evidenciam desempenho inferior a seus pares (LADD apud PAPALIA, 1998).

Grande parte dessas relações entre pares na escola ocorre durante as atividades motoras presentes no mundo infantil. A atividade motora auxilia na desinibição infantil, atuando como facilitadora no processo de aquisição das potencialidades individuais (ROSADAS, 1989), conduzindo a criança, de acordo com Ferreira Neto (1995), à descoberta de sua expressão individual, fora da ingerência dos adul-

Movimento, Porto Alegre, v. 11, n. 1, p.89-117, janeiro/abril de 2005 
tos. Para a criança Portadora de Necessidade Especial (PNE) essa prerrogativa se fortalece ainda mais, uma vez que a atividade motora propicia o desenvolvimento de habilidades comunicativas por meio do exercício de julgar, avaliar e trocar idéias em grupos (ADAMS 1985), bem como a superação das dificuldades, auxiliando a mesma na conquista da autonomia e da confiança (MINISTÉRIO DA EDUCAÇÃO E CULTURA, 1981).

A autoconfiança, a crença pessoal para a realização com sucesso de um comportamento desejado (WEINBERG e GOULD, 2001), possibilita à criança maior motivação, concentração e dedicação à tarefa, facilitando a resolução de problemas. Quando a autoconfiança está fragilizada, a criança tende a preocupar-se sobre como os outros a estão vendo, e não se percebe, muitas vezes, competente para a realização da tarefa, limitando a sua participação ou desistindo da mesma. A criança carente de autoconfiança tende a depender do sucesso para motivar-se, percebendo o fracasso como uma condenação ao seu valor próprio. Ao enfrentar novas tarefas, essa criança, ao invés de sentir-se desafiada para solucionar problemas, desiste ou volta-se para a realização de tarefas mais fáceis (HARTER, 1978, 1982).

Nessa perspectiva, Gallahue e Ozmun (2001) sugerem que a aquisição de habilidades motoras fundamentais, as quais em sua totalidade constituem-se no desafio maior do desenvolvimento motor na idade escolar, tornar-se um facilitador na construção da autoconfiança infantil. A prática motora, além de otimizar o desenvolvimento motor, amplia e aprofunda as relações sociais entre crianças, fortalece os níveis de autoconfiança e diminui a incidência de atos agressivos (MACHADO, 2002), comumente evidenciados após frustração (BEE, 1996), rejeição, provocação, ansiedade e tensão (RODRIGUES; CAMPOS; MANNING apud DIAS, 1996). Na diversidade das ações motoras e na resolução de problemas intrínseca às mesmas (LUFI e PARISH-PLASS apud BECKER Jr., 2000), a criança torna-se menos egocêntrica, aprendendo a expressar-se verbalmente, aumentando a ocorrência de comportamentos cooperativos e diminuindo a incidência de agressões físicas (PAPALIA, 1998).

Alguns autores sugerem que a diminuição da agressividade, na prática motora, talvez seja decorrente do aumento das relações entre pares, do apoio social experienciado e da diminuição da rejeição sofrida pelas crianças (BECKER Jr., 2000; BEE, 1996; MACHADO, 2002). Além disso, experienciar sentimentos de pertencer a um grupo que valoriza seus sentimentos e suas necessidades (TRIAN, 1997) é fundamental no processo de socialização. Por meio

Movimento, Porto Alegre, v. 11, n. 1, p.89-117, janeiro/abril de 2005 
da educação social, somos preparados a viver em sociedade, dando prioridade ao todo antes das necessidades pessoais (FREITAG, 1977), propiciando, na educação física, de acordo com Hurtado (1983) e Piccolo (1995), oportunidades para que crianças aprendam a conviver e participar na sociedade.

Portanto, a implementação de programas que ampliem e sustentem as diferentes formas de interações sociais de crianças PNE e não-PNE é imprescindível ao ensino inclusivo. Fortalecer a responsabilidade social e pessoal de crianças que freqüentam programas de educação física por meio de estratégias simples que propiciem oportunidades para: 1) a tomada de consciência das propostas do programa; 2) a vivência de experiências motoras em propostas e desafios relevantes; 3) a escolha de atitudes consideradas adequadas socialmente; 4) a resolução de problemas; 5) a auto-reflexão sobre o que foi feito em relação aos objetivos propostos; e 6) o aconselhamento do aluno sobre problemas específicos durante as atividades pode conduzir crianças a aprenderem acerca dos papéis sociais adequados ao contexto em que vivem, guiando o desenvolvimento de habilidades necessárias para a integração social (HELLISON e TEMPLIN, 1991).

Conviver e respeitar as diferenças, fundamental na socialização do indivíduo, tornam-se imprescindíveis frente às possibilidades da educação inclusiva, que tem como paradigma a inclusão de todos, independentemente do talento, da deficiência, da origem socioeconômica ou cultural, em ambientes provedores, onde as necessidades de todos os alunos são consideradas e satisfeitas (KARAGIANNIS et al., 1999). Embora com grandes avanços, as propostas inclusivas têm encontrado obstáculos cotidianos a serem ultrapassados tais como a não-aceitação de PNE pelos alunos típicos, bem como a atitude dos pais de crianças PNE, os quais muitas vezes têm dificuldades de lidar com a inclusão, no sentido de não quererem expor os problemas de seus filhos para os outros (HORVAT, 1990). Na tentativa de não afetar a autoconfiança dos PNE, geralmente, os pais dessas crianças acabam por superprotegêlas, impedindo-as de participarem das atividades, acentuando ainda mais as diferenças entre pares.

Hovart (1990) sugere que, para encorajar atitudes positivas de pais e alunos frente ao estigma da diferença, é necessária a promoção de oportunidades de integração. Nas oportunidades de interação inclusiva, os PNE têm oportunidades de preparar-se para viver em comunidade; e a sociedade aprende a valorizar a diversidade, fortalecendo o preceito da necessidade de serem criadas oportunidades

Movimento, Porto Alegre, v. 11, n. 1, p.89-117, janeiro/abril de 2005 
iguais para todos. Em ambientes inclusivos, o cuidado com o outro é oportunizado desenvolvendo nas crianças atitudes, habilidades e valores necessários para a vida em comunidade (KARAGIANNIS et al., 1999). Vários são os benefícios vivenciados por todos em ambientes inclusivos, entre os quais, segundo O'Brien e O'Brien (1999), podem ser citados estes: 1) a descoberta de características comuns entre pessoas que parecem e agem de maneira diferente; 2) o orgulho em ajudar alguém a conquistar ganhos importantes aparentemente impossíveis; 3) a oportunidade de cuidar do outro; 4) a promoção da igualdade e da superação da segregação; 5) o desenvolvimento de habilidades de resolução cooperativa dos problemas de relacionamento, comunicação e instrução; 6) a superação do medo das diferenças; 7) o aprender a lidar com comportamentos difíceis; e 8) o propiciar apoio um ao outro durante períodos de dificuldade.

Durante o decorrer das aulas, o ambiente inclusivo oferece, ainda, oportunidades de prática e observação de habilidades que talvez não estejam presentes em ambientes segregados (ZITTEL e McCUBBIN, 1996). O contexto inclusivo, por apresentar uma maior complexidade de tarefas (VICENT et al., apud ZITTEL e McCUBBIN 1996) e por integrar crianças PNE junto aos seus pares de desenvolvimento típico (BRICKER apud ZITTEL \& MCCUBBIN, 1996), oportuniza o desenvolvimento de todas as crianças por meio da cooperação e da integração social. É importante, ainda, ressaltar que a literatura contemporânea apresenta resultados positivos - benefícios motores, cognitivos e sociais - decorrentes de programas motores para crianças com atrasos (HAMILTON et al., 1999; RIMMER e KELLY, 1989; SAYERS et al., 2002; VALENTINI, 2002; VALENTINI e RUDIS SIL, 2004a) e benefícios semelhantes para PNE em propostas inclusivas (VALENTINI e RUDISSIL, 2004b). Em geral, esses programas evidenciem resultados significativos e importantes no desenvolvimento e qualidade de vida dos participantes, tendo como fonte de avaliação testes padronizados, os quais são aplicados durante o processo interventino e ou no início e final do programa. Outras fontes importantes da efetividade desses programas, como, por exemplo, os pais e professores, entretanto, têm sido pouco pesquisados. A pouca disponibilidade dos pais e professores em envolverem-se em sessões de entrevistas que podem alongar-se por horas ou ainda dias, ou ainda dificuldades na sistematização, redução e organização dos dados provenientes das entrevistas, podem ser alguns dos fatores que têm limitado a implementação de pesquisas com este delineamento metodológico. É importante ressaltar que pais e professores vivenciam o cotidiano da criança, sendo qualificados para observar, categorizar e relatar mudanças que ocorrem no desenvol-

Movimento, Porto Alegre, v. 11, n. 1, p.89-117, janeiro/abril de 2005 
vimento da criança, em decorrência do processo interventivo, de forma abrangente e não restrita a um único momento no tempo.

A investigação da percepção de pessoas significativas na vida da criança pode, portanto, propiciar a compreensão sobre o impacto da intervenção nas interações sociais, cognitivas e motoras cotidianas das mesmas, contribuindo para a estruturação de programas infantis que venham ao encontro das necessidades de todas as crianças, sejam as mesmas portadoras ou não de necessidades especiais. Destaca-se que um dos poucos exemplos na literatura atual, nessa perspectiva, é o estudo desenvolvido por Sayers et al. (2002), o qual enfocou a percepção dos pais sobre o impacto de uma intervenção no desenvolvimento de crianças com síndrome de Down. Nesse estudo, os pais implementaram um programa de intervenção motora com a supervisão universitária. Ao final do programa, os pais reportaram melhoras nos desenvolvimentos motor, social e cognitivo de seus filhos. Ressalta-se que essa intervenção ocorreu nas casas dos participantes, sendo, portanto, limitada em termos de integração social e inclusão. Até o presente, a percepção de pais e professores de possíveis benefícios de programas inclusivos não é reportada na literatura. Portanto, este estudo teve como objetivo investigar as percepções de pais e professores sobre possíveis mudanças cotidianas no comportamento social e a repercussão do processo inclusivo, em crianças PNE e não-PNE com atrasos motores que participaram de um programa de intervenção motora inclusivo.

\section{Método}

Participantes: Participaram desta pesquisa pais e professores de um grupo de 31 crianças, PNE e não-PNE, que freqüentaram um programa semestral de intervenção motora inclusiva, as quais apresentavam atrasos motores decorrentes da pobreza de experiências motoras, de dificuldades coordenativas e de diferentes tipos de deficiência - Paralisia Cerebral, Síndrome de Willians, Hidrocefacia, Síndrome de Down, lesões no cerebelo. Foram entrevistados 15 pais e seis professores, voluntários, somando um total de 32 entrevistas. Cada pai ou mãe respondeu por seu filho; e apenas uma criança teve ambos, pais e professor, entrevistados. Todos os professores participantes fazem parte da rede pública de ensino, sendo que alguns deles responderam por mais de um aluno.

Instrumento de coleta de informações: Entrevistas semiestruturadas foram realizadas após o término da intervenção, as quais foram gravadas em fita cassete e transcritas na íntegra pelo

Movimento, Porto Alegre, v. 11, n. 1, p.89-117, janeiro/abril de 2005 
pesquisador. Duas questões norteadoras foram feitas para pais e professores: 1) Após o Programa de Intervenção Motora, você percebeu alguma mudança de comportamento social de seu filho com amigos, colegas, pais e professores?; 2) O Programa de Intervenção Motora foi realizado com crianças típicas e crianças portadoras de necessidades especiais. Como o processo de inclusão repercutiu em seu filho?

Programa de Intervenção Motora Inclusivo: A intervenção foi desenvolvida durante 14 semanas, tendo duas sessões por semana, com uma hora de duração cada. Cada sessão foi dividida em três momentos: 1) $8 \mathrm{~min}$. de introdução com revisão das habilidades motoras a serem trabalhadas e com o reforço de regras, as quais foram previamente estabelecidas pelo grupo e enfatizavam a cooperação e o respeito; 2) 45 min. de instrução e prática de atividades motoras em grupos e estações; 3$) 7$ min. de encerramento, com considerações do professor sobre o trabalho realizado e sobre o engajamento nas atividades, oportunidade em que o professor procurou instigar a reflexão das crianças com relação a atitudes de responsabilidade social e pessoal. O programa implementou a proposta metodológica do Contexto Motivacional para a Maestria desenvolvida por Valentini (2002), a qual enfatiza a autonomia, com o objetivo de influenciar a motivação da criança para a aprendizagem. Quando o presente estudo foi desenvolvido, estavam participando do programa 79 crianças (48 meninos e 31 meninas) com idades de 4 a 10 anos $(M=7,07, D P=1,34)$, sendo 19 PNE e 60 crianças não-PNE, as quais apresentavam, em uma avaliação inicial, atrasos motores detectados por meio do Test of Gross Motor Development proposto por Ulrich (2000).

\section{Resultados e Discussão}

A partir da fala dos entrevistados, verificaram-se convergências de significados que serviram de base para a formação de categorias que representam os temas abordados nas entrevistas: comportamento social e repercussão do processo inclusivo. Os discursos mais representativos dessas categorias serão apresentados e discutidos; e, visando à preservação de identidade das pessoas envolvidas, foram utilizados nomes fictícios. Para a redução de dados foram utilizados gráficos de freqüência que podem ser usados em pesquisas qualitativas que codifiquem categorias comportamentais (THOMAS e NELSON, 2002).

Comportamento social: Com relação a mudanças no comportamento social, nas percepções dos pais (Figura 1) e dos professores (Figura 2), ocorreram mudanças no que se refere ao aumento das

Movimento, Porto Alegre, v. 11, n. 1, p.89-117, janeiro/abril de 2005 
interações sociais, da autonomia, da confiança e da responsabilidade, bem como à diminuição de agressividade. Os dados referentes às categorias do comportamento social serão apresentados e discutidos a seguir.

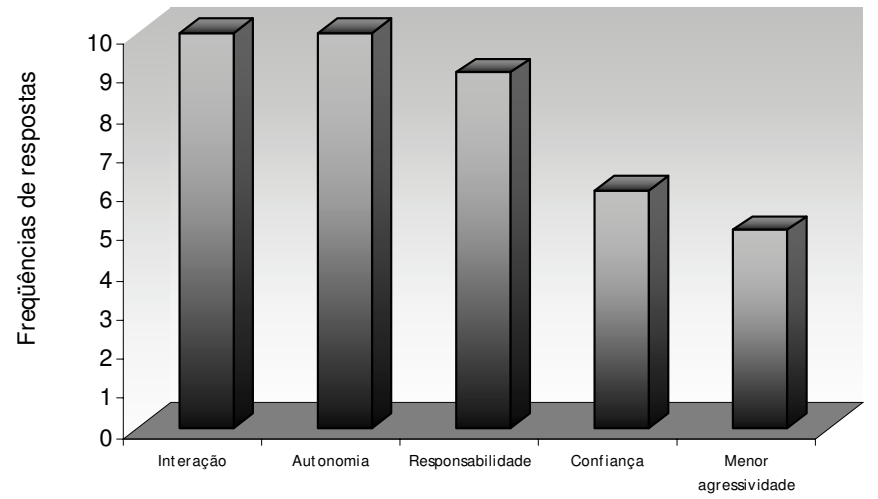

Figura 1 - Mudanças de comportamento social na percepção dos pais.

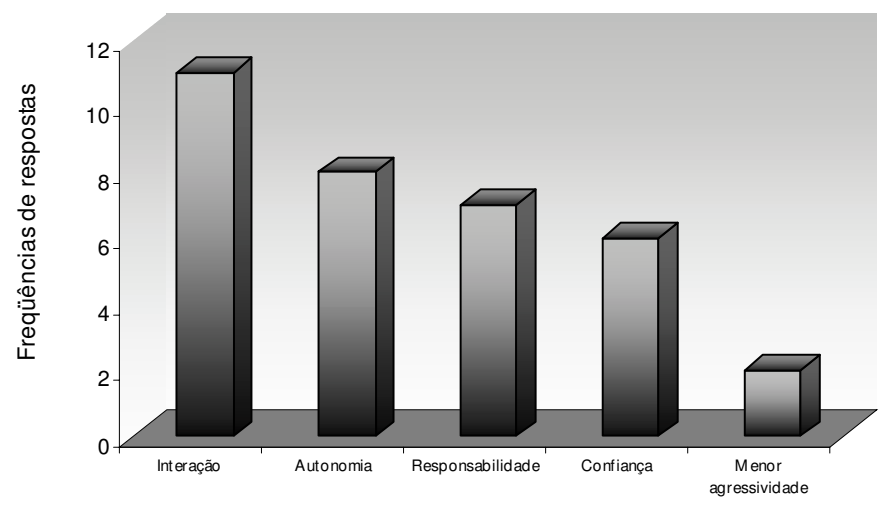

Figura 2 - Mudanças de comportamento social na percepção dos professores

Interação social: $\mathrm{O}$ enriquecimento das interações sociais foi relatado por pais e professores. Esses benefícios caracterizaram-se por melhoras de relacionamento entre pares, com pais, professores (Figura 3).

Movimento, Porto Alegre, v. 11, n. 1, p.89-117, janeiro/abril de 2005 


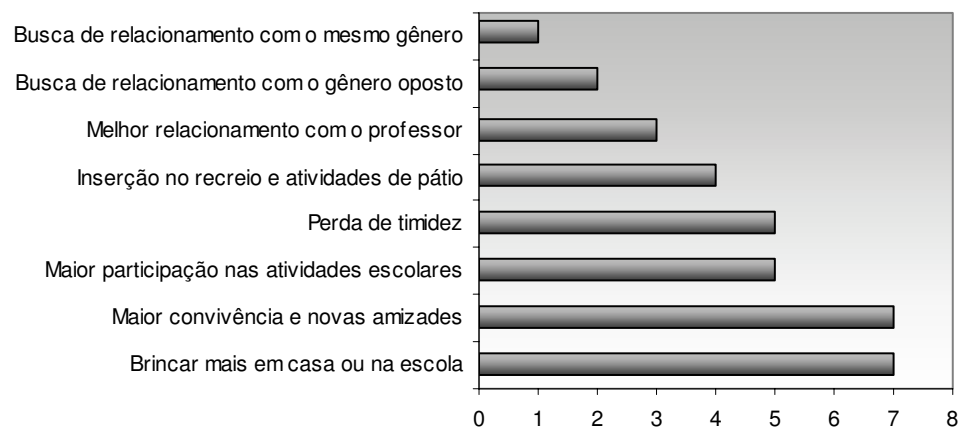

Figura 3 - Mudanças na interação social segundo pais e professores

Alguns relatos mais significativos sobre os benéficos na interação social, na percepção dos pais e professores, são apresentados e discutidos a seguir:

[...] é aquela criança que não sabe brincar, que não tem paciência, né; é tudo um minuto, senta elevanta; então com essa concentração que ele teve, ele consegue sentar e desenvolver uma brincadeira, faz com que aproxima dos amigos, porque é a própria criança que discrimina, né. A queixa dele era essa: de não quererem brincar com ele; então a partir do momento em que ele consegue [...] ele tá se integrando ao grupo, ela tá conseguindo fazer amizade. (Mãe de André)

[...] como ele era mais devagar que os ou tros, ele não conseguia acompanhar na amarelinha, isso, ele não conseguia acompanhar, então ele sempre deixava, ele ficava no cantinho e não participava muito do grupo; e agora ele participa, ele busca, ele convida para brincar. (Mãe de José)

Os relatos das mães de André e José deixam explícito que as dificuldades que seus filhos apresentavam eram barreiras para a maior interação social entre eles e seus pares. A partir da intervenção, em que as crianças praticam suas habilidades, as mesmas começaram a acompanhar as outras crianças nos jogos e nas brincadeiras, o que permitiu uma aproximação maior com os colegas. Para algumas crianças que participaram da intervenção, assim como para André e José, atingir um desempenho motor adequado a sua faixa de desenvolvimento dependia apenas de oportunidades efetivas e cotidianas de prática motora, por meio das quais o nível de desenvolvimento potencial de cada criança, conforme sugere Vygotsky (1998), foi conquistado quando a solução de problemas foi estimulada sob a orientação de adultos ou em colaboração com companheiros mais capazes, fato ocorrido durante as sessões interventivas.

Movimento, Porto Alegre, v. 11, n. 1, p.89-117, janeiro/abril de 2005 
Além disso, o sucesso do movimento realizado pela criança é uma das condições para que a mesma socialize com seus pares (REID, 1987; WILLIANS, 1983 apud RIMMER e KELLY, 1989). A oportunidade de interagir com outras crianças possibilita o aprendizado de relações significativas na infância (PAPALIA, 1998). Os relatos de um pai e de um professor, apresentados a seguir, enfatizam essa perspectiva.

Ele não gostava de ir à aula, na escolinha dele, não se adaptava bem aos colegas. Gostava de vir aqui, lá na escolinha não. Aí umas três semanas atrás ele não faltou mais às aulas na escolinha, deu uma melhorada. De repente as crianças da escolinha já tinham outro aspecto dele, e aqui ele se misturou mais com as outras crianças, então aceitou mais as outras, né, e ele foi aceito pelas outras crianças, vice e versa: melhorou bastante. (Mãe de Marcelo)

A Antonia, ela era uma criança que ela ficava de baixo da mesa, né, era uma criança que ela não se integrava muito. Ela teve mais acesso, ela começou a inventar brincadeira, ela brincava nos brinquedos de pátio, junto com os alunos e não sozinha. (Professora de Antonia)

Os relatos reforçam que a exposição a outras crianças criou oportunidades para a resolução de problemas de relacionamento. É importante enfatizar que, muitas vezes, crianças com atrasos de desenvolvimento acabam não interagindo com outras por falta de oportunidades ou por restrições da própria família, que limitam essas interações devido a tais atrasos. A professora de Antônia relata que, a partir da intervenção sua aluna obteve acesso em diferentes grupos sociais, vivenciando oportunidades de interagir com crianças fora do seu círculo de amizades convencionais. Fato que a incentivou a enfrentar seus problemas de relacionamento mediante a interação com vários modelos de comportamento (PAPALIA, 1998). Já a oportunidade de desenvolver novas amizades, experimentada por Marcelo durante a intervenção, ajudou-o a superar os problemas de relacionamento na escola e, conseqüentemente, diminui a incidência de faltas e de atitudes de negação e aversão ao espaço escolar (LADD apud PAPALIA, 1998).

Além disso, por meio da construção das novas amizades algumas crianças aumentaram a variabilidade das habilidades comunicativas, sociais e cognitivas, graças à capacidades dessas amizades de proporcionar sensações de proteção e bem-estar (GRENOTSCHEYER apud BISHOP, 1998). As atividades propostas instigaram crianças mais quietas e isoladas a brincarem, participarem e aprofundarem relações, sendo que algumas delas saíram do isolamento social em que viviam, conforme os relatos a seguir:

Movimento, Porto Alegre, v. 11, n. 1, p.89-117, janeiro/abril de 2005 
Ela se relaciona melhor com as amiguinhas, ela tá com amizades, ela agora tá fazendo laços mais profundos de amizade na escola [...] (Mãe de Luiza)

Ele era uma criança isolada [...] com os colegas também. Ele não brincava ali, nem com os bonecos dele ele não brincava; agora ele tá brincando, agora ele já tá se inteirando, participando das atividades [...] (Pai de Luis)

Eu notei assim que ele passou a participar da aula, né. Ele não participava, ele era uma criança que ficava quieta ou fingindo que tava quieto por de baixo da mesa [...] (Professora de Rodolfo)

As oportunidades de interagir nos jogos e as brincadeiras com pares do mesmo gênero foram uma experiência importante para Roberto, na percepção de sua professora:

ORobertonão se relacionava com, com quase todos os colegas não. A preferência do Roberto era brincar com as meninas; então assim, ó, ele, ele mudou, mudou realmente: agora no final ele tava brincando mais com os guris, participando de outros tipos de atividade, tá, de correr, de pular, de saltar [...] (Professora de Roberto)

A exposição e a interação de Roberto nos jogos motores e em conversas nos grupos de amigos do mesmo gênero, propiciadas nas sessões interventivas, oportunizaram-lhe uma maior identificação e incorporação de comportamentos adequados ao seu gênero (PAPALIA, 1998), conseqüentemente aumentando o leque de suas relações sociais.

É interessante, ainda, ressaltar que a relação professor-aluno é também de fundamental importância para que os objetivos do ensino sejam atingidos (HELLISON, 2003), e que, na percepção de pais e professores, mudanças nas interações também foram observadas em relação a adultos significativos na vida dessa criança, conforme os discursos que seguem:

[...] porque a Carla não tava acompanhando, veio de outra escola e não tava acompanhando a turma, e a professora foi para cima dela, e elas tavam meio que acompanhando a turma, e a professora foi para cima dela, e elas tavam meio que
se distanciando. Depois que ela foi indicada para o programa que ela começou a acompanhar mais, elas começaram a se relacionar melhor. (Mãe de Carla)

[...] ele é uma criança assim, muito muito tímida. Eu não conseguia que ele falasse absolutamente quase nada comigo. Aos pouquinho eu notei essa mudança comigo, né; não houve assim tantas mudanças com os colegas, mas eu notei mais a mudança com... com a minha pessoa. (Professora de Frederico)

As inúmeras oportunidades de interagir com adultos, vivenciadas no cotidiano da intervenção, propiciaram a Carla, de acordo com a percepção de sua mãe, tranqüilidade para engajar-se em novos relacionamentos, inclusive com a professora. Experiência similar é reportada pela professora de Felipe, a qual constatou melhora na relação social entre ela e seu aluno no decorrer do período interventivo.

Movimento, Porto Alegre, v. 11, n. 1, p.89-1 17, janeiro/abril de 2005 
Os relatos evidenciam benefícios no desenvolvimento social construídos a partir da ampliação de oportunidades de interação social entre indivíduos (PAPALIA, 1998). De modo geral, nas percepções dos pais e professores, ficou evidenciado que a intervenção - seja por meio da prática motora ou da diversidade das experiências sociais oferecidas - enriqueceu as interações sociais entre as crianças participantes, pessoas adultas significativas e pares provenientes de variados contextos.

Autonomia: A construção da autonomia em relação às atividades do cotidiano, as tarefas escolares e deslocamentos em espaços físicos da escola foram categorias de significados identificadas nas falas dos pais (Figura 4) e dos professores (Figura 5) das crianças participantes da intervenção.

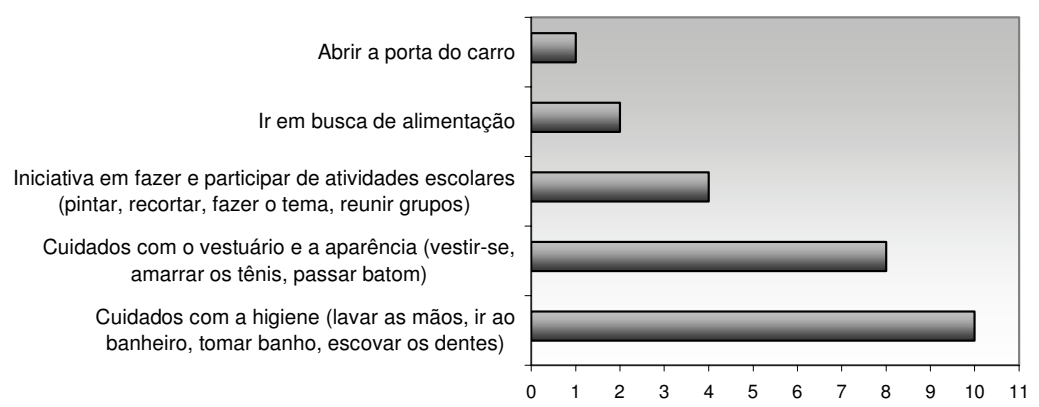

Figura 4 - Mudanças na autonomia segundo a percepção dos pais.

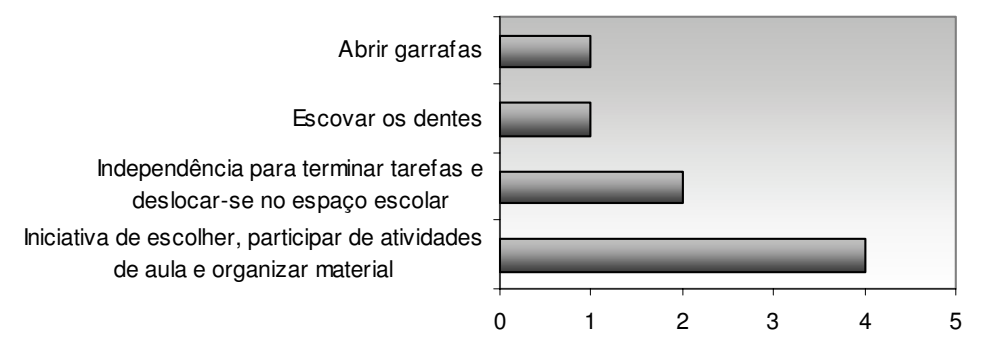

Figura 5 - Mudanças na autonomia segundo os professores.

A seguir são apresentados e discutidos os relatos mais representativos dos pais e professores em relação à construção da autonomia de seus filhos e alunos.

[...] ela faz coisas que ela não fazia antes sozinha [...] ela mudou muito: ela se pentia, ela vai ao banheiro, ela passa batom sozinha, coisa queé uma dificuldade ela passar batom. Isso vai da coordenação, porque ela se borrava toda para passar batom, e ela

Movimento, Porto Alegre, v. 11, n. 1, p.89-117, janeiro/abril de 2005 
fica muito feliz que ela consegue passar um batom sem borrar. Ela tem essa autoconfiança, essa liberdade de fazer mais sozinhas as coisas; porque antes era muito assim: me ajuda aqui, me alcança ali, me veste aqui. Isso melhorou muito como programa; ela pedia mais e hoje ela pede menos ajuda. (Mãe de Linda)

Ela támais possível de fazer coisas, sabe, ela se sente mais autônoma, se sentemais capaz. Não tem dúvida que ela ta com bastante mais autonomia, depois do programa. Antes, por exemplo, para lavar as mãozinhas ela ia na pia e não conseguia fazer isso aqui sabe, ela ficava trancada; agora não: ela vai, estende, faz arte na pia; se eu me descuido ela na pia brincando fazendo molhaçada [... ] (Mãe de Luiza) Ah! Iniciativa também melhorou, que às vezes eu quero, quero vestir ele ou quero dar banho nele: "não mãe, não precisa mais, agora eu já sei". Eu te amarro o teu calçado; "eu também já sei". Às vezes não amarra direito, mais ele já, ele diz, "eu já sei, eu aprendi. (Mãe de Fernando)

[...] vai tomar o banho, ele já sabe que tem que tirar a roupa e ir para o banheiro, ta. Eu [...] "André vai" [...] primeira coisa ele tira a roupa; tu não tem que tá lembrando: ele já tá mais [...] tomando as iniciativas para as atividades que ele faz no dia-a-dia." (Mãe de André)

Os pais relataram, principalmente, que seus filhos evidenciaram melhoras consideráveis em relação à realização das tarefas cotidianas. É importante enfatizar que a criança que apresenta atraso motor, dependendo do grau, pode ficar impossibilitada de realizar atividades da vida diária, gerando dependência de adultos, o que pode levar a complexos de inferioridade (MINISTÉRIO DA EDUCAÇÃO E CULTURA, 1981). Em contrapartida, a atividade motora orientada oferece oportunidades para a melhora das habilidades motoras amplas (HAMILTON et al., 1999; RIMMER e KELLY, 1989; SAYERS et al., 2002; VALENTINI, 2002), oportunizando conseqüentes melhoras em relação às atividades da vida diária (ADAMS, 1985). Linda, conforme relata a sua mãe, agora consegue pentearse, ir ao banheiro e passar batom sozinha. Nos outros relatos, Luiza já consegue lavar as mãos; Fernando já consegue amarrar o sapato, tomar banho e vestir-se sozinho; e André já tira a roupa sem ajuda da mãe para tomar banho. Conseguindo realizar atividades que antes pareciam intransponíveis, a criança beneficia-se, também, no aspecto emocional. Linda ficou muito feliz por ter conseguido passar o batom sem borrar, o que antes era muito difícili; enquanto que Luiza, que não conseguia lavar as mãos, agora fica fazendo brincadeiras na pia. Observa-se que, ao enfrentar e conseguir superar novos desafios, a criança fica extasiada, repetindo esse feito várias vezes, demonstrando grande satisfação e alegria por ter superado um obstáculo (BEE, 1996).

A construção da autonomia nas atividades escolares também foi percebida por alguns pais e professores como uma categoria importante de significado, conforme seus relatos a seguir:

Movimento, Porto Alegre, v. 11, n. 1, p.89-1 17, janeiro/abril de 2005 
Ela tinha muita dificuldade para acompanhar a turma, ela ficava esperando a mãe para fazer o tema seja lá a hora que a mãe chegasse do trabalho; e ela... nisso ela mudou bastante: eu chegava ela já tinha feito [...] (Mãe de Carla)

[...] no caso de ela pegar um livro para recortar, pegar um desenho para pintar, que antes ela não fazia, era insegura nisso; e agora ela não se importa se vai sair da linha se vai ficar na linha: ela tem tomado iniciativa neste aspecto. (Mãe de Bela)

Ele ficou mais independente e aí ele passou a ser o primeiro a terminar e aí passou a mostrar para os outros "ó eu to conseguindo, tu não tá conseguindo": ele vibra assim com o progresso que ele teve. (Professora de Rodolfo)

[...] ele não sabia ir ao banheiro: "para que lado eu vou? Para que lado éo refeitório [...] não sei" [...] levem ele lá.; e depois não: ele passou até a ser ajudante. (Professora de Jorge)

Observa-se no relato de pais e professores que a prática motora, por meio de seus mecanismos formativos, conforme sugerem Rosadas (1989) e Ferreira Neto (1995), conduziu as crianças a descobrirem suas próprias potencialidades, fato que repercutiu efetivamente no engajamento com autonomia em diferentes atividades. Conforme sugerem os relatos de pais e professores, Carla esperava pela mãe para fazer o tema de casa. No decorrer da intervenção, melhorou seu desempenho escolar, conseguindo fazer seu tema sem a supervisão de adultos. Já Bela não tinha iniciativa de recortar e pintar e sentia-se insegura por não conseguir realizar estas tarefas com perfeição. Bela participou das mais diversas atividades motoras de manipulação; conseqüentemente, melhorou sua motricidade fina (HAMILTON et al, 1999; RIMMER e KELLY, 1989; VALENTINI e RUDISILL, 2004a), o que, possivelmente, re-percutiu na confiança e na conseqüente autonomia para realizar as tarefas de recorte e pintura (ADAMS, 1985). No caso de Rodrigo, este se tornou mais independente, conseguindo realizar as tarefas antes de seus colegas. Ele vibra com o progresso que obtém, chegando a mostrar o feito para seus colegas, pois a conquista parece refletir no seu autoconceito (BEE, 1996).

O último relato, o da professora de Jorge, sugere que a autonomia de seu aluno mudou em relação aos deslocamentos nos espaços físicos da escola. Jorge, que não conseguia orientar-se para ir ao banheiro, passou, após a intervenção, até a ajudar a levar os outros ao local. A prática motora cotidiana promoveu incrementos nas funções interpretativas e sensórias do aluno por meio da aquisição de habilidades de orientação, tais como noções de tempo, espaço e direção (ADAMS, 1985). Hellison (2003) reforça essa perspectiva afirmando que a estratégia de deixar o aluno deslocarse por conta própria em aulas dispostas em circuito oferece a oportunidade de a criança desenvolver maior independência na Edu-

Movimento, Porto Alegre, v. 11, n. 1, p.89-117, janeiro/abril de 2005 
cação Física e, conseqüentemente, autonomia em suas tarefas de deslocamento do cotidiano.

Confiança: A confiança foi outra categoria de significado que emergiu na fala de pais e professores, os quais perceberam que seus filhos e alunos tornaram-se mais confiantes na sua capacidade de realizar as atividades caseiras e escolares, conforme exemplificado nos discursos a seguir:

[...] antes ela nem ia pular corda, tinha medo de errar, agora ela não tem mais medo de errar, porque ela se sente mais confiante no que faz. Porque antes acontecia assim: vamos supor, hã as amigas estão brincando de pular corda, e ela não conseguia, então já vinha aquela "ah ela não consegue... ah ela não...", então aquilo só era uma negativa para ela. Agora ela vai, ela pode não pular até dez vezes a corda, mas ela consegue uma, e as amigas já notam isso e já não taxam como não consegue; então ela já vai confiante no que faz. (Mãe de Bela)

Eu acho que ele se sente bem confiante, por essas coisas que eu já falei, por causa que ele vêas outras crianças fazendo certas coisas que ele não fazia que agora ele também pode fazer. (Mãe de Fernando)

Eu achei que ele ficou mais autoconfiante, ele, né; porque antes eu acho que ele não conseguia fazer, então ele se achava... (Professora de Rodolfo)

Por meio das entrevistas, observa-se que crianças que não conseguiam realizar tarefas motoras que seus pares realizavam, evitavam efetivamente brincadeiras e tarefas escolares (GALLAHUE e OZMUN, 2001; HARTER, 1978, 1982). A partir da intervenção, as crianças praticaram as mais variadas habilidades motoras, adquirindo confiança para brincar com os colegas. A crença que Bela, Fernando e Rodolfo construíram sobre suas capacidades de realizarem as tarefas propostas repercutiu na construção da autoconfiança (WEINBERG e GOULD, 2001), uma vez que os mesmos tornaram-se mais competentes por meio da prática motora, resultando na aproximação com pares e professores.

Diminuição da agressividade: Pais e professores de algumas crianças fizeram referência, também, à diminuição de agressividade de seus filhos e alunos após o término do programa, exemplificados pelos discursos a seguir:

Ela era muito agressiva, né; ela é meio grande; ela ficou bem mais sociável. Eu era chamado freqüentemente pela diretora lá. A té a diretora falou: "a professora não mandou mais para a minha sala"; então tá melhor. (Pai de Beatriz)

Eu notei assim que [...] que ele no início ele era um pouco [...] bem mais agressivo; depois no [...], assim, do programa, eu notei que ele tentava às vezes a até apaziguar dentro da sala de aula alguma [...] alguma briguinha, alguma coisa assim, tentando evitar o conflito; isso eu notei nele. (Professora de Dado)

Movimento, Porto Alegre, v. 11, n. 1, p.89-117, janeiro/abril de 2005 
Estudos prévios (LUFI e PARISH-PLASS apud BECKER JR., 2000; MACHADO, 2002) têm evidenciado que a prática motora pode ser usada como um meio eficiente para a diminuição da agressividade por meio das diferentes ações geradas por essa atividade. Como exemplo, Becker Jr. (2000) sugere que no contexto da atividade motora a criança recebe o apoio social dos demais participantes, fato que repercutiu na diminuição da agressividade. Beatriz não foi mais mandada para a sala da diretora, e Dado procura assumir um comportamento apaziguador frente aos conflitos que se estabelecem em sala de aula. O aumento na sociabilidade dessas crianças pode ter sido um dos fatores, segundo a percepção dos pais e professores, responsáveis pela diminuição da agressividade de ambos. Entretanto, a diminuição da agressividade, para alguns pais e professores, está relacionada com o aumento do respeito pelo outro, enfatizado no contexto de ensino da intervenção. Os discursos que seguem versam sobre esse assunto:

[...] no colégio também sempre tava brigando assim com um ou com outro, assim, não esperava a vez dele; e agora ele espera [...] (Mãe de Fernando)

[...] ele não queria dividir e, se eu obrigasse, ele queria dar nos outros; então essa parte de dar nos outros ele diminuiu isso, então ele não agredia mais, ele emprestava $[\ldots]$ (Professora de Jorge)

Fernando aprendeu a esperar por sua vez nas atividades escolares, e Jorge começou a compartilhar materiais com os colegas. Os dois relatos sugerem que o trabalho interventivo propiciou oportunidades para que as crianças exercitassem e refletissem sobre o respeito para com os outros. Conforme sugere Hellison (2003), o respeito é o nível mais básico da construção da socialização entre pares. Para alcançar um mínimo de interação social, a criança tem que aprender a respeitar os direitos e os sentimentos dos outros, o que, na percepção de pais e professores, auxiliou na diminuição de comportamentos agressivos.

Responsabilidade: Organizar, guardar e arrumar brinquedos e materiais tanto na escola como em casa, ou seja, responsabilizar-se por pequenas tarefas, foi reportado por pais (Figura 6) e professores (Figura 7) como um fator de modificação que ocorreu durante o período interventivo. 


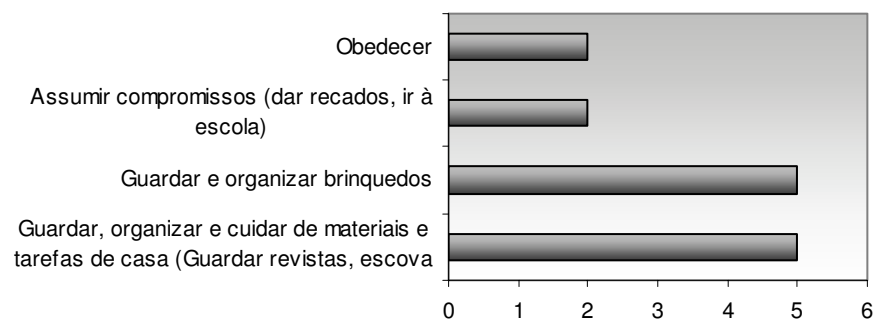

Figura 6 - Mudanças na responsabilidade na percepção dos pais.

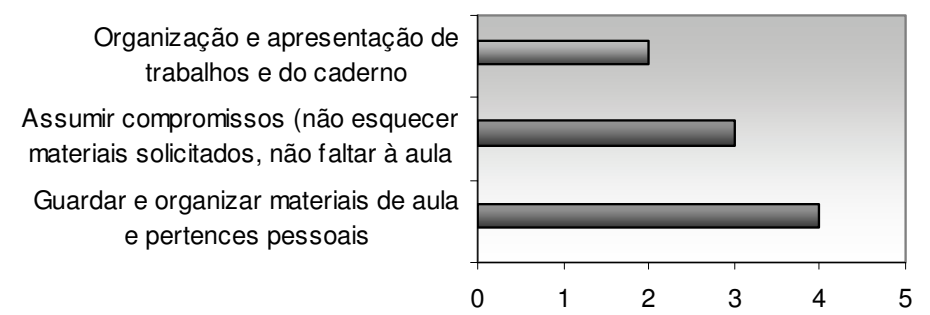

Figura 7 - Mudanças na responsabilidade na percepção dos professores.

Alguns exemplos mais significativos dos relatos de pais e professores seguem abaixo:

[...] antes do programa eu já fazia isso, só que antes eu guardava muito mais brinquedos do que ela; e agora não: ela agora guarda tudo, e eu realmente só ajudo [...] (Mãe de Luiza)

Olha, melhorou na organização, porque ela sempre foi assim, ó: pegava o brinquedo, deixava ali, hã; agora ela tem guardado, ela mesmo, "ó mãe já arrumei", eu... opa! Até me assusto assim [...] (Mãe de Bela)

Ele escovava os dentes, largava a escova em cima da pia, o xampu ficava no chão, entendeu; aí ele tá mais organizado... (Mãe de Rodolfo)

[...] a própria organização dela, de caderno, dos livros, era tudo assim levado de... atirava um livro, jogava outro, fazia uma coisa; ela começou a se organizar nesta parte também, no material dela. (Professora de Andréa)

As crianças, ao serem desafiadas a assumir níveis mais elevados de responsabilidade durante a prática motora interventiva, conscientizaram-se acerca de suas responsabilidades individuais e coletivas em tarefas simples, porém importantes no dia-a-dia dessas crianças (HELLISON, 2003). Por meio de estratégias específicas durante a intervenção, os alunos foram incentivados a trabalhar de modo cooperativo e independente, cuidar de materiais, fazer esco-

Movimento, Porto Alegre, v. 11, n. 1, p.89-1 17, janeiro/abril de 2005 
lhas, respeitar os outros, refletir sobre o trabalho realizado e assumir a responsabilidade por suas atitudes.

O não-esquecimento de compromissos também foi relatado por alguns entrevistados:

Hã, quando tem alguma coisa para fazer assim ela se compromete, tipo, teve uma sessão lá na escolinha, "amanhã tem coisa lá na escolinha, eu não quero faltar, porque tem isso para fazer"; então ela se sentiu responsável porque tinha esse compromisso na escola e ela não queria faltar. (Mãe de Luciane)

[...] antes ela, digamos assim, o pessoal dava telefonema, ligava, e ela não dava recado; agora ela... ó mãe, fulano ligou [...] (Mãe de Marta)

[...] era uma criança que não trazia tema, já começou a trazer, ele trazia os temas, materiais solicitados ele trazia assim, isso aímudou [...] (Professora de Frederico)

De acordo com a percepção dos pais, Luciane assumiu a responsabilidade de não faltar às aulas, Marta começou a transmitir os recados, e Frederico começou a levar para a escola as matérias e deveres de casa que antes eram sempre esquecidos. Embora reconheçamos que a brincadeira é a principal vivência de uma criança, concordamos com Freitag (1977) que obrigações e compromissos têm que ser aprendidos na infância para uma convivência social saudável. As atividades motoras propostas em grupos, em que a diversidade foi presente, ofereceram condições para que as crianças refletissem sobre seus compromissos e limites pessoais, e se conscientizassem de que melhoras pessoais dependem do envolvimento e do esforço próprio (HELLISON, 2003). Ainda mais, é por meio de relações recíprocas e de respeito mútuo, em que a criança infere que seus interesses são mais adequadamente satisfeitos por relações cooperativas, que a mesma constrói sua autonomia. Somente quando são oportunizadas à criança opções de escolha e poder de decisão, é que ela tem possibilidade de cooperar voluntariamente com os outros, e, assim, construir seu próprio sistema moral de convicções (PIAGET, 1977) e fortalecer sua responsabilidade pessoal e social.

Repercussão do processo inclusivo: Para inferirmos sobre o impacto causado pela inclusão nas crianças que participaram da intervenção, a segunda pergunta - O Programa de Intervenção Motora foi realizado com crianças típicas e crianças portadoras de necessidades especiais. Como o processo de inclusão repercutiu em seu filho? - foi proposta apenas para os pais, pois a maioria dos professores não sabia que se tratava de um programa inclusivo, portanto não teriam condições de responder com clareza acerca desse assunto. As unidades de significados mais freqüentes que convergiram para a formação das categorias a partir da pergunta

Movimento, Porto Alegre, v. 11, n. 1, p.89-117, janeiro/abril de 2005 
norteadora foram estas: aceitar as diferenças dos outros; conviver com a diferença; dar valor a sua condição; perceber que os outros também têm dificuldades e superar as próprias dificuldades observando outros e com a ajuda dos outros.

Seis dos 15 pais entrevistados são responsáveis por crianças PNE. Os discursos mostram alguns benefícios em comum sugeridos pelos pais de crianças típicas e pais de crianças portadoras de necessidades especiais acerca da inclusão; porém, alguns benefícios ocorreram com mais freqüência para as crianças típicas (Figura 8), enquanto que outros apareceram com mais freqüência para crianças PNE (Figura 9). A seguir serão apresentadas e discutidas as percepções dos pais das crianças que participaram da intervenção, conforme as categorias de significado já referidas.

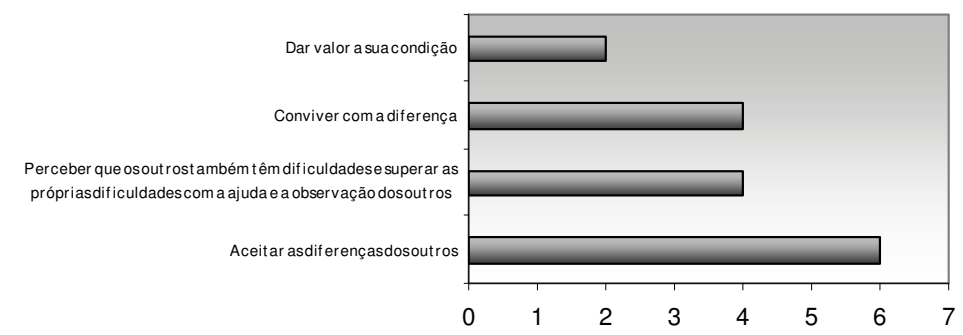

Figura 8 - Efeitos benéficos da inclusão na percepção de pais de crianças tipicas.

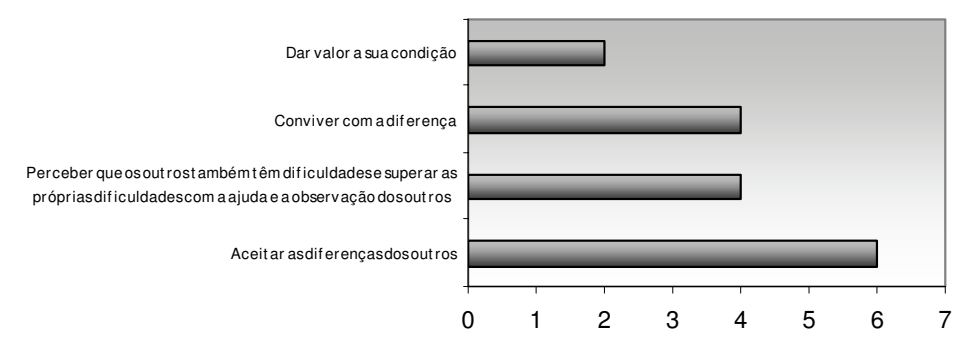

Figura 9 - Efeitos benéficos da inclusão na percepção de pais de crianças PNE.

Aceitar as diferenças dos outros: Por meio da percepção dos pais, constata-se que a maioria das crianças não notou as diferenças existentes entre elas, como mostram os relatos que seguem:

Movimento, Porto Alegre, v. 11, n. 1, p.89-117, janeiro/abril de 2005 
Ela sempre chegou falando muito bem de todos, contando de todos os colegas assim, sem diferença. (Mãe de Carla)

[...] para ele acho que não faz diferença: para ele é todo mundo igual. (Mãe de Fernando)

Não, ele só gostava de vim para brincar, não falou nada dos colegas... (Pais de Luis)

A aceitação do grupo perante os problemas individuais de alguns colegas é crucial para que o processo inclusivo obtenha sucesso (HORVAT, 1990). Nesse sentido, é importante observar que a maioria dos pais entrevistados respondeu que seus filhos não demonstraram nenhum problema quanto à aceitação das diferenças de seus colegas. Conforme os pais de Carla, Fernando e Luis, a diversidade de atrasos motores apresentados por cada um dos participantes da intervenção não foi obstáculo para o sucesso do processo inclusivo. As crianças não-PNE não evidenciaram atitudes negativas, conforme tem sido relatado na literatura (HORVAT, 1990), não constituindo esse fator um obstáculo para o ensino inclusivo. Nessa perspectiva, a não-observação das diferenças dos outros oportunizou que as crianças PNE praticassem as diversas habilidades motoras em um ambiente complexo em termos de tarefas propostas e rico em modelos, por meio da diversidade, oferecendo oportunidades mais efetivas de aprendizagem e interação social do que o ambiente segregado (ZITTEL e MCCUBBIN, 1996; VALENTINI e RUDISSIL, 2004b).

Conviver com a diferença: Saber conviver com a diferença apareceu com freqüência nos discursos dos pais de crianças que não apresentam necessidades especiais, conforme os relatos:

[...] ele aprendeu muito a conviver com as pessoas que têm dificuldades né. Hojeele convive melhor do que eu, ele aceita, ele assimila melhor doqueeu [...] (Mãe de José)

[...] aí preconceito que eles saibam lhe dar uns com os outros, né. Acho que fez bem: ela fez amizade assim com todo mundo assim [...] (Mãe de Carla)

A literatura atual tem apontado como benefício da inclusão o resgate da valorização do vínculo social entre indivíduos diferentes (KARAGIANNIS et al., 1999), a superação do medo das diferenças (O'BREIN, 1999) e a promoção da igualdade (KARAGIANNIS et al., 1999; O'BREIN, 1999). Aceitar e conviver com a diferença remetenos a um exercício social de profunda dificuldade, pois, historicamente, as diferenças não têm sido compreendidas, e os indivíduos PNE acabam sendo marginalizados pela sociedade (KARAGIANNIS et al., 1999; STOBAUS e MOSQUERA, 2000). Esse estigma está presente na entrevista da mãe de José, que relata abertamente a sua dificuldade em lidar com crianças PNE. Podemos inferir, pelo seu

Movimento, Porto Alegre, v. 11, n. 1, p.89-117, janeiro/abril de 2005 
discurso, que seu filho também tinha as mesmas dificuldades da mãe; porém que José, por meio das oportunidades que lhe foram propiciadas de conviver com crianças portadoras de necessidades especiais, aprendeu a conviver com essas diferenças, lidando melhor do que a mãe com a diversidade. Da mesma forma, o discurso da mãe de Carla fala em vencer o preconceito, mais uma vez demonstrando a força que tem esse estigma. Esse preconceito desafia a escola a desenvolver estratégias metodológicas que proporcionem, a todas as crianças, oportunidades de aprender a conviver com a diferença e, com isso, construir valores de igualdade e de aceitação da diversidade.

Dar valor a sua condição: Dar valor a sua condição, de não portar necessidades especiais, também foi uma categoria importante relatada por pais de duas crianças típicas. Abaixo, seguemse os relatos:

[... ] só que ela não... não tem nem a met... nada do que elas tem, que ela é perfeita, e que às vezes ela fica reclamando das coisas, para ela enxergar que as coisas são assim, né [...] (Mãe de Luciane)

[...] que ele não se aproximava muito né, das crianças, das pessoas com problemas; ao contrário ele ficava, sabe, se questionando; hoje não, talvez isso até valorize que ele é uma pessoa perfeitamente, né. (Mãe de José)

A mãe de Luciane sugere que a intervenção inclusiva pode ter ajudado sua filha a enxergar que seus problemas talvez sejam pequenos frente às dificuldades de outros. No relato da mãe de José, esta sugere que seu filho antes tinha medo de aproximar-se de crianças PNE e que hoje, além de não ter mais essa dificuldade, valoriza o fato de não possuir necessidades especiais. As experiências vividas talvez tenham ajudado Luciane e José a refletirem e interiorizarem novos valores. É importante ressaltar que, de acordo com Vigotsky (1994), é no processo de internalização, ou seja, de transformação de um processo interpessoal em um processo intrapessoal, que ocorre o desenvolvimento. Dessa forma, ao conviverem com as restrições evidenciadas pelas crianças PNE na intervenção - nível interpessoal - Luciano e José construíram novas percepções sobre suas habilidades - nível intrapessoal -, valorizando-as. Ao valorizar a sua condição, a criança típica está refletindo também sobre a diversidade da sociedade em que vive (KARAGIANNIS at al., 1999) e, com isso, compreendendo melhor a situação de seus colegas PNE (HORVAT, 1990), superando restrições pessoais e crescendo como uma criança que conscientiza-se das diferentes contribuições pessoais que indivíduos diferentes trazem para a sociedade.

Movimento, Porto Alegre, v. 11, n. 1, p.89-117, janeiro/abril de 2005 
Perceber que os outros também têm dificuldades e superar as dificuldades com a ajuda e a observação dos outros: Todas as crianças participantes da intervenção possuíam algum tipo de atraso motor, sendo ou não portadoras de necessidades especiais. As dificuldades próprias e dos outros foram percebidas por várias crianças e relatadas por pais de crianças portadoras e não-portadoras de necessidades especiais, exemplificados pelos relatos:

Então, assim, ela foi percebendo que daqui a pouco ela não conseguia pularo bambolê, mas ela pulava o tijolinho, o outro pulava o bambolê, mas ela não, né, e assim queela comentava, né. Entãoeu viqueela percebeu quenãoésóela, porqueno meio que eu vivo ela é a única criança que tem esse problema [...] (Mãe de Bela)

[...] pra enxergar exatamenteisso, quecada uméde uma maneira, que cada um tem suas limitações, tem aquela que corre e não fala direito, né [...] (Mãe de Virginia)

A oportunidade de trabalhar com a diversidade propiciou a observação das diversas restrições individuais. A Mãe de Bela relata que sua filha se deu conta de que não é a única a ter problemas. Bela percebeu que outros colegas tinham dificuldades diferentes das dela e que também apresentavam dificuldades em superar alguns obstáculos. A mãe de Virginia observa que cada um tem uma maneira diferente de ser, "tem aquele que corre e não fala direito", e que o convívio de sua filha com crianças que apresentam outras dificuldades foi enriquecedor no sentido de despertá-la para esse fenômeno. Os relatos dos pais sugerem que, no ambiente inclusivo da intervenção, as crianças beneficiaramse pela valorização da diversidade. A inclusão promoveu, ainda, oportunidades para que as crianças se deparassem com diferentes situações em que a resolução de problemas era necessária frente às dificuldades de realizar uma ação (KARAGIANNIS et al., 1999). Ao conviverem com crianças que também evidenciam restrições motoras, algumas crianças sentiram-se otimistas, observando que, assim como os outros, elas também poderiam superar as suas dificuldades, conforme os relatos abaixo da mãe de Marta e Fernando:

[...] eu não falei só da minha filha: eu falei dos outros, para cada um deles verem é, vê essas dificuldades, né, que os outros também têm dificuldades, eque ela pode superar essa dificuldade, e que os outros também podem, cada um indo superando as suas dificuldades [...] (Mãe de Marta)

Eu acho que ébom, eu acho que ébem bom para ele, que, para ele vêcomoéque é; uns tem uns problema outros tem outro, mas todo mundo consegue chegar lá, chegar a melhorar bastante com ajuda dos outros assim, vai melhorando. (Mãe de Fernando)

Movimento, Porto Alegre, v. 11, n. 1, p.89-117, janeiro/abril de 2005 
É importante ressaltar que, de acordo com Bandura (1979), a aprendizagem da criança é facilitada por meio de processos de modelação, em que novos comportamentos são adquiridos, e padrões de respostas existentes são modificados mediante a observação do comportamento de outras pessoas e de suas conseqüências. Durante a prática motora, ambientes inclusivos propiciam a observação, entre as crianças, de níveis diferenciados de habilidades motoras e comportamentos que não são encontrados em ambientes segregados, onde atrasos são comuns (VALENTINI e RUDISSIL, 2004b; ZITTEL e McCUBBIN, 1996). Espelhando-se no exemplo de outros, algumas crianças conseguiram modificar padrões de comportamento sociais e motores que os levaram à superação de algumas dificuldades. Para Fernando, a diversidade de dificuldades observadas nos colegas incentivou-o a superar suas próprias dificuldades. Além disso, sua mãe enfatiza que ele melhorou não só por meio da observação, mas também com a ajuda dos outros. Nesse sentido, concordamos com Vygotsky (1998) quando sugere que, somente na cooperação com companheiros mais capazes ou assistida por adultos, a criança consegue resolver certos problemas que não conseguiria resolver de forma independente, exercitando funções que ainda não amadureceram totalmente. A intervenção inclusiva ofereceu oportunidades para que os pares cuidassem e ajudassem uns aos outros, conquistando, em cooperação, ganhos importantes em seu desenvolvimento.

\section{Considerações finais}

Ao longo deste estudo, mediado pela percepção de pais e professores, foram constatadas importantes mudanças positivas na interação social, na autonomia, na confiança, na responsabilidade, no convívio com a diversidade e na diminuição da agressividade de crianças com atrasos motores que participaram de um Programa de Intervenção Motora Inclusivo. Por meio das experiências motoras, as crianças conquistaram uma maior proximidade com seus pares, enriquecendo suas interações sociais em jogos e brincadeiras. As oportunidades oferecidas de práticas motoras, rotineiras e adequadas ao desenvolvimento de todos, auxiliaram na autonomia das crianças para a realização de tarefas diversas em casa ou na escola. A autonomia do movimento também gerou a sensação de bemestar em algumas crianças por terem conseguido realizar tarefas que antes não conseguiam; afinal, talvez não tenha nada mais singelo e significativo para uma menina do que poder passar batom sem borrar, assim como conseguido por Lisandra.

Movimento, Porto Alegre, v. 11, n. 1, p.89-117, janeiro/abril de 2005 
O aumento da confiança foi outro importante benefício conquistado pelas crianças e relatado por pais e professores, os quais observaram que, com o enriquecimento da motricidade, algumas crianças perderam o medo de realizar as tarefas, não mais desistindo das mesmas. Além disso, a diminuição da agressividade e o aumento de responsabilidade também foram benefícios relatados pelos entrevistados. Durante a intervenção, as crianças foram motivadas a respeitar os direitos dos outros, a participar das atividades com esforço e a cuidar de si e dos outros. Possivelmente, as estratégias metodológicas adotadas na intervenção auxiliaram no desenvolvimento de interações sociais mais significativas para todas as crianças. Construindo valores de respeito e cooperação, muitas crianças diminuíram o seu comportamento agressivo, tornaram-se mais obedientes, organizadas em suas tarefas caseiras e/ou escolares, mais responsáveis no assumir compromissos do mundo infantil.

O impacto causado pela inclusão sobre as crianças participantes da intervenção também foi relatado como uma experiência positiva pelos pais. Aprender a conviver com a diversidade foi um dos aspectos significativos reportados pelos pais. Muitas vezes, o preconceito para com as pessoas portadoras de necessidades especiais é passado de pai para filho, dificultando a percepção de que, indiferentemente das restrições individuais, somos iguais e temos os mesmos direitos. Em um dos relatos, a mãe de uma criança admite que, após a intervenção, seu filho aprendeu a lidar com essa dificuldade própria, enquanto que ela ainda não tinha superado a mesma. Tal fato reforça a necessidade de implementação de programas inclusivos para a superação do medo da diferença. A diversidade de dificuldades motoras apresentadas pelas crianças durante a intervenção serviu também como ponto de referência para algumas crianças, conforme seus pais sugeriram. Observando as dificuldades de outras, certas crianças deram-se conta de que não são as únicas a terem dificuldades e que podem, portanto, superá-las. Durante a intervenção, pela observação das diferenças pessoais, a criança refletiu sobre si mesma, aprendendo a lidar melhor consigo e com o outro, conforme foi inferido por pais dos participantes.

Outro aspecto importante nos relatos dos entrevistados foi o fato de que a grande maioria das crianças, típicas ou portadoras de necessidades especiais, não se importaram com as diferenças apresentadas entre elas. O fato de certas crianças correrem bem, algumas não conseguirem pular e outras nem andar direito não

Movimento, Porto Alegre, v. 11, n. 1, p.89-117, janeiro/abril de 2005 
foi motivo para que elas deixassem de participar e integrar-se às atividades propostas. Isso demonstra que as atitudes positivas das crianças típicas para com as crianças portadoras de necessidades especiais podem tornar-se um instrumento valioso no processo inclusivo, quando são priorizadas propostas pedagógicas que enfatizam a cooperação entre pares, como a que foi implementada no presente estudo.

Na percepção de seus pais e professores, o Programa de Intervenção Motora e sua característica inclusiva proporcionou às crianças participantes riqueza na diversidade das experiências motoras e da convivência social, auxiliando-as a tornarem-se mais aptas para administrar tarefas cotidianas. Poucas pesquisas têm sido desenvolvidas nesse enfoque, pela dificuldade de acompanhar o dia-a-dia da criança nos espaços sociais que ela freqüenta. Dessa maneira, a metodologia empregada no presente estudo investigando a percepção de pessoas próximas e significativas na vida da criança (pais e professores) constitui um instrumento eficiente na obtenção de informações, as quais embora possam estar carregadas de sentido próprio, de transferências e ansiedades, relatam a experiência vivida pela criança no decorrer do processo interventivo.

Ainda mais, é importante ampliar as bases investigativas, utilizando-se de métodos quantitativos e qualitativos para aprofundar o conhecimento sobre o impacto da intervenção na vida dos participantes, bem como prover subsídios para a reorganização da tarefa interventiva, quando necessário. Futuras pesquisas podem contribuir também na investigação das possíveis mudanças nas ações de familiares, frente a uma criança que agindo diferente passa a mudar o mundo que a cerca. Ainda mais, como a criança transfere as novas habilidades motoras para o mundo do brinquedo livre é outra fonte possível e significativa de investigação. A complexidade da prática interventiva se beneficia de diferentes olhares investigativos, contribuição que esperamos ter feito com o presente estudo.

Movimento, Porto Alegre, v. 11, n. 1, p.89-117, janeiro/abril de 2005 
Parents and teacher's perceptions of the influence of an inclusive motor skill intervention program in the social behavior of children with and without disabilities Abstract: The purpose of this research is to investigate the perceptions of parents and teachers about possible changes in social behavior and the repercussion of the inclusion process in children with or without disability, with motor delays, that participated in an inclusive motor intervention during 14 weeks. From a semistructured interview, conducted with parents and teachers, positive changes were evidenced regarding social interaction, autonomy, trustworthy, responsibility, as well as a decrease in aggressiveness. With regard to the inclusive process, acquaintanceship and acceptance of difference allowed some of the children to overcome motor and social difficulties.

Keywords: Motor Intervention, Motor Delays, Social Behavior, Inclusion.

Percepción de padres y maestros en la influencia
de um programa motor inclusivo en el comporta-
miento social de niños portadores y no portadores
de necessidades especiales
Resumen: Esta investigación tiene como principal objeti-
vo observary estudiar las percepciones de padres y maes-
tros acerca de los posibles cambios en el comportamiento
social bien como la repercusión del proceso inclusivo de
niños, portadores o no de necesidades especiales, con
retrasos motores, que participaran de una intervención
motora inclusiva con duración de 14 semanas. Desde una
entrevista semi estructurada, de la cual participaron pa-
dres y maestros de los niños que frecuentaron el progra-
ma, se constataram cambios positivos cuanto a las sigui-
entes características en esos niños: interacción social,
autonomía, confianza, responsabilidad, bien como la dismi-
nución de la agresividad. Con relación al proceso inclusi-
vo, la convivencia y la aceptación de la diferencia permi-
tieron la superación de las dificultades motoras y sociales
de algunos de los niños.
Palabras-clave: Intervención Motora, Retrasos Motores,
Comportamiento Social, Inclusión.
Comportamiento Social, Inclusión. 


\section{Referências}

ADAMS, Ronald. Jogos, Esportes e Exercícios para o Deficiente Físico. São Paulo: 1985.

BANDURA, A. Modificação do comportamento. Rio de Janeiro: Interamericana, 1979.

BECKER Jr., Benno. Manual de Psicologia do Esporte e Exercício. Porto Alegre: Novaprova, 2000.

BEE, Helen. A criança em desenvolvimento. Porto Alegre: Artes Médicas, 1996.

BISHOP, Kathryn D. Promovendo Amizades. In: STAINBACK, Susan; STAINBACK, William. Inclusão: Um Guia Para Educadores. Porto Alegre: Artes Médicas, 1999. p. 184-199.

DIAS, Katia P. Educação Física x Violência. Rio de Janeiro: Sprint, 1996.

FERREIRA NETO, Carlos A. Motricidade e Jogo na Infância. Rio de Janeiro: Sprint, 1995.

FREITAG, Bárbara. Escola, Estado e Sociedade. São Paulo: Edart, 1977.

GALLAHUE, David; OZMUN, John C. Compreendendo o Desenvolvimento Mo tor: Bebês, Crianças, Adolescentes e Adultos. São Paulo: Phorte Editora, 2001.

HAMILTON, Michelle; GOODWAY, Jacqueline; HAUBENSTRICKER, John. Parent-Assisted Instruction in a Motor Skill Program for At-Risk Preschool Children. Adapted Physical Activity Quarterly,v 16,n 4, p.415-426,1999.

HARTER, S. Effectance Motivation reconsidered: Towards a Developmental Model. Human Development, 21, p. 34-64, 1978.

HARTER, S. The Perceveid Competence Scale for Children. Child Development 53, p. 87-97, 1982.

HELLISON, Donald R. Teaching Responsibility Through Physical Activity. Champaign, IL: Human Kinetics, 2003

HELLISON, Donald R.; TEMPLIN, Thomas J. A Reflective Approach to Physical Education. Champaign, IL: Human Kinetics, 1991.

HORVAT, Michel. Physical Education and Sport for Exceptional Students. Dubuque, IA: Wm. C. Brown, 1990.

HURTADO, J.G.G.M. O Ensino da Educação Física. Curitiba: Educa/Editer, 1983

KARAGIANNIS, Anastasios; STAINBACK, Susan; STAINBACK, William. Fundamentos do Ensino Inclusivo. In: STAINBACK, Susan e STAINBACK, William. Inclusão: Um Guia Para Educadores. Porto Alegre: Artes Médicas, 1999. p. 21-34.

MACHADO, Patrícia B. Comportamento Infantil. Porto Alegre: Mediação, 2002.

MINISTÉRIO DA EDUCACÃO E CULTURA. Atividade Física para o Deficiente. Secretaria de Educação Física e Desportos,1981.

Movimento, Porto Alegre, v. 11, n. 1, p.89-1 17, janeiro/abril de 2005 
O'BRIEN, John; O'BRIEN, Connie L. A Inclusão como uma Força para a Renovação da Escola. In: PAPALIA, Diane E.; OLDS, Sally W. Desenvolvimento Humano. Porto Alegre: Artes Médicas, 1998.

PAYNE, Gregory V.; ISAACS, Larry D. Human Motor Development: a Lifespan Approach. 5 ed.USA: McGraw-Hill, 2002.

PIAGET, J. O Julgamento Moral na Criança. Sao Paulo: Mestre Jou, 1977.

PICCOLO, V.L.N. Educação Física Escolar: Ser... ou não Ter. Campinas: Editora da UNICAMP, 1995.

RIMMER, James H; KELLY, Luke E. Gross Motor Development in Preschool Children with Learning Disabilities. Adapted Physical Activity Quarterly, v.6, n 3, p. 268-279, 1989.

ROSADAS, Sidney C. Atividade Física Adaptada e Jogos Esportivos para o Deficiente. Rio de Janeiro: Atheneu, 1989.

SAYERS, L. K.; COWDEN, J. E.; SHERRIL, C. Parent's Perceptions of Motor Interventions for Infants and Toddlers with Down Syndrome. Adapted Physical Activity Quarterly, v.19, n 2, p. 199-219, 2002.

STOBAUS, Claus D.; MOSQUERA, Juan J. M. Educação Inclusiva: um novo olhar sobre educação especial. Revista Educação, n.42, nov. 2000. p. 129-142.

THOMAS, Jerry R.; NELSON, Jack K. Métodos de Pesquisa em Atividade Física. Porto Alegre: Artes Médicas, 2002.

ULRICH, D. The Test of Gross Motor Development. Auntin, TX: Pro-Ed, 2000.

VALENTINI, Nadia C. A Influência de uma Intervenção Motora com Contexto de Motivação para a Maestria no Desenvolvimento Motor de Crianças Portadoras ou não de Necessidades Especiais: Uma Perspectiva Inclusiva. In: III Seminário de Comportamento Motor. Gramado. Anais. 2002.

VALENTINI, Nadia C.; RUDISILL, Mary. E. Motivacional Climate, Motor-skill Development and Perceived Competence: Two Studies of Developmental Delayed Kindergarten Children. Journal of Teaching in Physical Education. v. 23, p.216-234, 2004a.

An Inclusive Mastery Climate Intervention and the Motor Development of Children With and Without Disabilities. Adapted Physical Activity Quarterly. v. 21, p330-347, 2004b.

VYGOTSKY, L. S. A formação Social da Mente: O Desenvolvimento dos Processos Psicológicos Superiores. São Paulo: Martins Fontes, 1998.

WEINBERG, R. S.; GOULD, D. Fundamentos da Psicologia do Esporte e do Exercício. Porto Alegre: Artmed, 2001.

ZITTEL, Lauriece L.; McCUBBIN, Jeffrey A. Effect of an Integrated Physical Education Setting on Motor Performance of Preschool Children with Developmental Delays. Adapted Physical Activity Quarterly, v.13, n 3, p. 316-333, 1996.

Movimento, Porto Alegre, v. 11, n. 1, p.89-117, janeiro/abril de 2005 

Jardim Botânico Proto Alegre - 90670-002 nadiacv@esef.ufrgs.br

Movimento, Porto Alegre, v. 11, n. 1, p.89-117, janeiro/abril de 2005 